\title{
Influência de brasileiros famosos no boicote de consumidores que usam redes sociais virtuais
}

\section{Influence of famous Brazilians in consumer boycott that use virtual social networks}

\author{
Breno de Paula Andrade Cruz \\ Professor da Universidade Federal Rural do Rio de Janeiro - UFRRJ \\ e-mail: brenocruz@yahoo.com.br \\ Steven Dutt Ross \\ Ebape - FGV \\ Estatístico pela Ence - IBGE \\ Joel Joukin Machado Braga \\ Universidade Federal Rural do Rio de Janeiro - UFRRJ \\ Bolsista de Iniciação Científica - UFRRJ \\ Daniel Martins Abelha \\ Universidade Federal Rural do Rio de Janeiro - UFRRJ \\ Bolsista de Iniciação Científica - UFRRJ
}

Artigo Recebido em 19.07.2011. Revisado por pares em 12.11.2011. Recomendado em 12.11.2011 por Edson Roberto Scharf, Editor Responsável. Publicado em 30.06.2012. Organização responsável pelo periódico: FURB Universidade de Blumenau (www.furb.br/rn)

\section{Resumo}

Boicote é o ato de o consumidor deixar de comprar um produto ou serviço por não concordar com um posicionamento de uma empresa (Klein, Smith e John, 2004), o que pode gerar perdas financeiras a uma empresa. Verificando as lacunas na literatura nacional tem-se como objetivo geral identificar grupos de pessoas famosas no Brasil que podem influenciar consumidores usuários de redes sociais a boicotar. Uma amostra com 272 consumidores usuários de redes sociais foi utilizada neste estudo. Dentre 162 pessoas famosas citadas na fase de pré-teste, 62 foram consideradas no estudo final. Estas pessoas foram classificadas em oito grupos de acordo com sua presença na mídia (jornalistas, entretenimento, religiosos, atletas, atores, cantores, políticos e personalidades). Dentre alguns resultados, têm-se: (a) o
\end{abstract}

ranking de pessoas famosas que mais influenciaram os consumidores usuários de redes sociais da amostra; (b) as correlações entre os grupos de pessoas famosas; e, (c) o cruzamento da relação da influência das pessoas famosas na participação de um boicote pelo consumidor com variáveis demográficas.

Palavras-Chaves: Boicote; Brasileiros (as) famosos (as); Redes Sociais Virtuais.

\begin{abstract}
Boycott is a repudiated behavior which is characterized by the consumer's decision of not buying a product, service or brand (Klein, Smith e John, 2004), possibly leading to financial loss to the company. Identifying the gaps in the boycott's theory in the national context, this paper investigates the influence of the Brazilian famous people in the con-
\end{abstract}


sumers who use social networking and the possibility of boycotting. A sample with 272 consumers was used in this study. In the first phase it was identified 162 famous people but only 62 were considered in the final phase. These famous people were classified in eight groups in accord to your media's presence (journalists, entertainment, monks, athletics, actors, singers, politicians and personalities). As the main outcomes of this investigation we have: (a) the ranking of Brazilian famous people who have more influence on consumers who use social networking; (b) the correlation between the groups of famous people; and (c) the crossing of the groups and the influence of famous people on consumer boycott and this relationship with demographic variables.

Key-Words: Boycott; Brazilian famous people; social networking

\section{Justificativa e Relevância do Tema}

As transformações ocorridas nos últimos 20 anos suscitam investigações acadêmicas nas mais diferentes perspectivas no campo da Administração. Uma das temáticas ainda pouco discutidas no país e que carece de estudos exploratórios e empíricos é a temática do boicote dos consumidores. $\mathrm{O}$ primeiro estudo focado na temática e com embasamento teórico forte no contexto brasileiro é o de Cruz (2011a). O autor fez um levantamento teórico aprofundado sobre a temática do boicote dos consumidores relacionada à Responsabilidade Social Corporativa e apresentou proposições para futuras pesquisas no Brasil relacionadas ao boicote de consumidores.

O termo boicote é usado para caracterizar um comportamento de repúdio de um ou mais consumidores em relação a um produto, serviço ou empresa. Klein, Smith e John (2004) definem boicote como uma ação de um cliente ou grupo de clientes que deixa(m) de comprar um produto, serviço ou marca pelo fato dos valores ou atuação da empresa estar desconexos ou distantes dos seus valores pessoais ou coletivos. Assim, a principal característica na demarcação do conceito de boicote é a atitude de não compra de um consumidor (Klein,
Smith \& John, 2004; Friedman, 1999; Soule, 2009; e, Cruz, 2011a).

Esta temática se torna relevante para a área de Marketing no Brasil primeiro pela lacuna de conhecimento do tema (perspectiva acadêmica) e, depois, pelo fato de algumas empresas terem sofrido boicote de consumidores como medida de retaliação às ações dessas. No contexto internacional não faltam exemplos como de casos de empresas que sofreram boicote e já foram abordados na literatura de comportamento do consumidor - conforme pode ser visto em Knight \& Pretty (2000), Palazzo \& Basu (2004) e Smith et al (2010). Por se caracterizar uma lacuna na área, no contexto nacional apenas os trabalhos de Cruz (2011a; 2011b) apresentam empresas que sofreram boicote por parte de seus consumidores.

Não menos importante que o boicote dos consumidores, as redes sociais virtuais, como lócus em que o usuário troca informações com outros usuários de maneira eficiente e dinâmica contribuindo para uma 'cascata de informações' (Solomon, 2011), permitem que seja criado um espaço de interação em que as plataformas online auxiliem nos contatos interpessoais virtuais, independente do espaço físico ou geográfico em que os membros da rede se encontram (Tomaél, Alcará \& Chiara, 2005). Levando-se em consideração a associação da temática boicote com as redes sociais virtuais a partir do contexto brasileiro, é apresentada a pergunta de pesquisa deste artigo: quais pessoas famosas no Brasil influenciam consumidores de redes sociais virtuais a boicotarem uma empresa mediante seu discurso escrito ou falado? Como objetivos específicos, têm-se: (i) listar as 10 pessoas famosas que mais influenciam o boicote de consumidores; (ii) classificar as pessoas famosas em grupos homogêneos de acordo com a atuação profissional; (iii) verificar a existência de correlação significativa entre os grupos criados; (iv) verificar as relações 
entre variáveis demográficas e influência de uma pessoa famosa no boicote do consumidor; e, (v) sugerir novas questões para futuras pesquisa na temática do boicote dos consumidores.

Além desta introdução, o trabalho contém ainda mais quatro seções. A próxima seção apresenta o arcabouço teórico sobre o boicote de consumidores e também sobre redes sociais virtuais. A terceira seção detalha o percurso metodológico adotado (tanto a fase qualitativa quanto a fase quantitativa). Já a quarta seção apresenta os resultados empíricos da pesquisa de campo. Por fim, a quinta seção apresenta as implicações teóricas e gerenciais, além das limitações do estudo e sugestões para pesquisas futuras.

\section{Fundamentação Teórica}

Esta seção do trabalho apresenta o arcabouço teórico que norteia a demarcação do conceito de boicote como ato do consumidor em deixar de comprar um produto ou serviço de uma empresa e também discute as características do lócus da pesquisa: as redes sociais virtuais.

\subsection{Boicote de Consumidores}

O termo boicote foi usado por volta de 1880, para designar uma retaliação organizada por pequenos comerciantes que negociavam com um grande fazendeiro americano, senhor Charles Boycott. A partir do momento que o grupo de pequenos comerciantes percebeu que poderia fazer uma retaliação ao fazendeiro deixando de comprar seus produtos mediantes suas exigências descabidas, usou-se pela primeira vez o termo boycott (Soule, 2009).

Klein, Smith \& John (2004) definem boicote como uma ação de um cliente ou grupo de clientes que deixa(m) de comprar um produto, serviço ou marca pelo fato dos valores ou atuação da empresa estarem des- conexos ou distantes dos seus valores pessoais ou coletivos. Assim, a principal característica na demarcação do conceito de boicote é a atitude de não compra de um consumidor.

O medo do boicote dos consumidores por parte de grandes empresas é explicado a partir de casos de grandes marcas como Nike, Coca Cola e Shell. No caso da Nike, por exemplo, que envolveu o escândalo da utilização de mão-de-obra infantil na China em sua cadeia de suprimentos, o boicote dos consumidores com apoio de uma ONG fez com que o CEO da empresa recebesse mais de 33 mil cartas solicitando mudanças nas condições de trabalho na cadeia de suprimentos da empresa (Palazzo $\&$ Basu, 2007). Este exemplo evidencia que a decisão de consumo pode afetar as práticas laborais (Smith et al 2010) de uma empresa ou de sua cadeia de suprimentos.

Outros casos empíricos demonstram também a força de um boicote. Por exemplo, por pressão de boicote de universidades americanas e canadenses, a Coca Cola teve que rever sua atuação na Colômbia no que diz respeito à violação de direitos humanos, uma vez que os contratos e produtos da empresa foram banidos de 20 universidades naqueles dois países (Kreyre, 2006 apud Palazzo \& Basu, 2007, p. 338-339). Já a Shell perdeu entre 10 e 15 milhões de dólares por dia no ano de 1999 pelo fato dos consumidores terem boicotado a empresa pelo caso Brent Spar (Knight \& Pretty, 2000). O GreenPeace apurou também que a Shell perdeu $7 \%$ de participação de mercado depois de não aderir ao Protocolo de Kyoto (Aaker, 2004).

A situação em que os valores pessoais do consumidor não correspondem aos valores organizacionais de uma empresa e que gera um comportamento de repúdio deste com relação a práticas de responsabilidade social, resultando em possíveis prejuízos tangíveis e intangíveis a uma marca é 
chamado de Backlash (Smith et al, 2010, p. 622). Conforme aponta Cruz (2011a), embora Backlash e boicote possam ser entendidos como sinônimos, entende-se que o boicote é um tipo de Backlash, pois este último pode incluir o boicote a partir do momento em que os atores além de protestarem podem deixar de consumir. De acordo com o Longman Dictionary of Contemporany English (2009), o termo Backlash na perspectiva sociológica diz respeito a uma "reação negativa de uma coletividade a uma ideia ou produto a partir de uma reflexão e não é somente ignorar algo, vai além ao propor uma rejeição". Já o boicote está relacionado ao ato de deixar de comprar algum produto.

As motivações para participar de um boicote podem ser diferentes entre cada grupo de consumidores ou até mesmo entre os consumidores que participam de um ato de boicote a uma empresa, produtos ou serviços. A literatura internacional aponta alguns tipos de boicotes que são motivados por questões ecológicas, religiosas, por minorias ou por razões econômicas relacionadas ao aumento do preço de um produto ou serviço (Friedman, 1999). O autor apresenta os tipos mais frequientes de boicotes nos Estados Unidos e na Inglaterra, sendo eles: econômico, religioso, minorias e ecológico.

A título de classificação, de acordo com Cruz (2011b), estes tipos de boicotes são divididos em duas dimensões. A primeira delas é a dimensão econômica, ou seja, os consumidores participam de um boicote pelo fato de discordarem do posicionamento da empresa em relação a variáveis econômicas (preço, imperfeição no mercado - monopólio, crise econômica). Já os boicotes relacionados às minorias ou a aspectos ecológicos e religiosos estão relacionados em uma segunda dimensão: boicotes ideológicos, que envolvem motivações psicossociais. Nesta dimensão são analisadas variáveis como pertencimento a um grupo, influência de familiares e amigos e os próprios valores pessoais do consumidor.

No passado, um dos primeiros relatos sobre a atitude de não comprar um produto por não concordar com a atuação da empresa se deu em 1773, quando a Coroa Inglesa resolveu taxar o chá e criou o monopólio. Para não comprar da empresa que obtinha a concessão, os colonos ingleses passaram a contrabandeá-lo (Soule, 2009). Assim, a 'Boston Tea Party' é o primeiro evento relatado na história em que se analisa a relação entre o monopólio e o sentimento e ação contra uma empresa.

$\mathrm{Na}$ Grécia, Barda \& Sardianou (2010) evidenciaram que mais de $50 \%$ dos consumidores gregos boicotaram produtos alimentícios após o aumento de preços no momento da crise financeira do país. Em reflexo ao boicote, os autores verificaram que produtos alimentícios como frutas, peixes e carnes foram os mais afetados, uma vez que $49 \%$ da amostra utilizada pelos pesquisadores informaram que são favoráveis ao boicote para evitar a formação de cartel.

Já na perspectiva do boicote ideológico, os motivos vão para além da variável econômica e podem variar de acordo com as características psicossociais de um grupo de consumidores. Alguns consumidores boicotam por não concordarem com a orientação socialmente responsável de uma empresa, como foi o caso da utilização de trabalho semiescravo pela Nike (Palazzo \& Basu, 2007); outros consumidores por considerarem posturas ambientalmente incorretas como no caso de derramamento de óleo da empresa Shell nos Estados Unidos na bacia de Brent Spar (Knight \& Pretty, 2000); e até por posicionamentos estratégicos não aceitos pelos consumidores, como no caso da Shell que perdeu 7\% de mercado ao deixar de aderir o Protocolo de Kyoto (Aaker, 2004). 
Partindo para as características dos consumidores, especificamente as variáveis demográficas, alguns autores já buscaram entender a relação destas variáveis com a variável "boicote do consumidor". Por exemplo, em relação ao sexo, Barda \& Sardianou (2010), verificaram que as mulheres, proporcionalmente, boicotavam mais que os homens gregos no momento de crise na Grécia e estudos apontam maior predisposição das mulheres em relação aos homens em consumir politicamente (Nielson, 2010; Stolle et al, 2005) - sendo o boicote uma forma de consumo político.

Quando analisada a variável renda do consumidor em relação ao comportamento de boicote, alguns autores apresentam resultados que demonstram o boicote a partir do aumento do preço em um produto ou serviço (Friedman, 1999; Barda \& Sardianou, 2010). Barda \& Sardianou (2010) verificaram que o aumento do preço de produtos alimentícios na Grécia estimulou o boicote dos consumidores. De acordo com Neilson (2010), a renda do consumidor apresenta correlação com o boicote, uma vez que na amostra analisada, verificou-se que esta variável influencia positivamente o ato de boicotar.

Outra variável demográfica que é analisada na temática do boicote é o nível educacional do consumidor. Neilson (2010) verificou que existe uma correlação positiva e significativa $(p<0,001)$ entre o nível educacional e o boicote dos consumidores. No modelo de regressão apresentado no texto, a variável nível educacional além de ser significativa e positiva tem uma influência de 0,18. Quando comparada com outras variáveis do modelo como renda e sexo, o coeficiente da variável comparativamente é relativamente superior.

Além das variáveis demográficas, outro fenômeno que deve ser analisado quando se aborda a temática dos boicotes dos consumidores é o lócus em que esta situação pode ser estimulada por meio dos consumidores e se tornar robusta: as redes sociais virtuais. O próximo item da revisão de literatura aborda as características deste lócus.

\subsection{Redes Sociais Virtuais}

O ser humano realiza conexões com outros indivíduos e estas conexões formam uma rede social. Com o avanço da tecnologia teve-se a elevação da comunicação a um nível virtual, o que desenvolveu em grande escala as redes sociais virtuais. A análise de redes sociais se aplica em qualquer assunto social empírico (Mizruchi, 2006) e atualmente tem sido discutida principalmente nas relações sociais virtuais por meio das plataformas como o Facebook, o Twitter e os blogs, dando suporte à comunicação mediada por computador (Tomaél, Alcará \& Chiara, 2005).

A definição de redes sociais é construída a partir das relações estruturadas entre os indivíduos. Marteleto (2001) define redes sociais como um grupo de participantes autônomos que unem e compartilham ideias e recursos baseados em interesses comuns. A formação de redes é peculiar ao ser humano, pois este constrói uma rede de relacionamentos em diversas esferas, como, profissional, familiar ou pessoal, e, essas relações são criadas de acordo com os interesses pessoais e modificadas de acordo com a trajetória do indivíduo (Tomaél, Alcará \& Chiara, 2005). Analisar, entender ou interpretar essas relações tem se tornado uma importante ferramenta de análise estratégica para as relações interorganizacionais (Mizruchi, 1992) e, no caso das redes sociais virtuais, para a empresa posicionar-se em relação aos seus consumidores (Packer, 2011). "A análise de redes é um tipo de sociologia estrutural que se baseia numa noção clara dos efeitos das relações sociais sobre o comportamento individual e grupal" (Mizruchi, 2006, p. 73). 
Embora o conceito de redes sociais seja amplamente discutido atualmente, inclusive fora do meio acadêmico em virtude do crescimento vertiginoso das redes sociais virtuais (Boyd \& Ellison, 2008), a análise de redes sociais não é um fenômeno recente conforme apontam alguns estudiosos do tema (Mizruchi, 2006; Tomaél, Alcará \& Chiara, 2005; Marteleto, 2001). As redes sociais têm sido estudadas a partir de diferentes contextos, como, por exemplo, dos movimentos sociais (Scherer-Warren, 1993), relações de poder de grupos organizacionais ou interorganizacionais (Balestrin \& Vargas, 2002) e até na perspectiva das milícias (Ribeiro \& Oliveira, 2010). Mais recentemente, de maneira ampla, as redes sociais têm sido estudadas no ambiente online em diferentes perspectivas, sendo o foco deste estudo a perspectiva gerencial conforme será discutido aqui.

Os estudos sobre redes sociais virtuais surgem não somente pela perspectiva acadêmica do assunto, mas, principalmente, pela intensidade que as mesmas têm sido utilizadas por diversos indivíduos em diferentes partes do mundo. O Brasil, por exemplo, teve mais de 39 milhões de usuários de redes sociais no ano de 2011, considerando que o universo total de usuários de Internet no país era de 46 milhões (Cruz, 2011). Nessas redes, os usuários divulgam voluntariamente produtos, criticam serviços ou empresas e ajudam a fortalecer movimentos de boicotes enquanto consumidores por meio da criação de comunidades antimarcas (Albuquerque et al, 2009),

No contexto da tecnologia da informação, as redes por meio de seu dinamismo, promovem o compartilhamento das informações e do conhecimento. De acordo com Boyd \& Ellison (2008) muitos sites construídos para serem redes sociais virtuais foram concebidos nas redes sociais preexistentes, como são os casos do Myspace e do Facebook. Outros foram construídos para que pessoas que não se conhecem previamente possam dividir visões políticas, pontos de vistas ou estabelecer laços profissionais. Alguns destes sites, para os autores, podem ser construídos tanto para compartilhar valores comuns (identidade racial, sexual ou religiosa) como para atrair pontos de vistas divergentes e gerar a discussão sobre um tema.

O espaço de interação, que é possibilitado por meio das plataformas online que auxiliam nos contatos interpessoais virtuais, independe de espaço físico ou geográfico dos membros na rede (Tomaél, Alcará \& Chiara, 2005). Em relação aos objetivos dos usuários em utilizar grandes redes sociais virtuais, Boyd \& Ellinson (2008) afirmam que muitos desses não estão à procura de novos amigos, isto é, muitos usuários querem estender para uma plataforma virtual sua rede social que já existe no mundo real. A Figura 1 apresenta uma linha do tempo em relação às principais redes sociais surgidas desde 1997.

As diferenças entre os públicos variam de acordo com o objetivo de cada rede social virtual, e, inclusive, com a localização dos participantes conforme pode ser analisado a seguir. Em 2004, o Myspace se tornou popular nos Estados Unidos pelo uso em massa dos adolescentes. No Brasil, antes de ter crescido rapidamente na Índia, o Orkut foi entre 2004 e 2011 à rede social com maior número de usuários. Já o Hi5 foi adotado em pequenos países da América Latina, e, o Bebo foi muito popular no Reino Unido, Nova Zelândia e Austrália (Boyd \& Ellinson, 2008). 


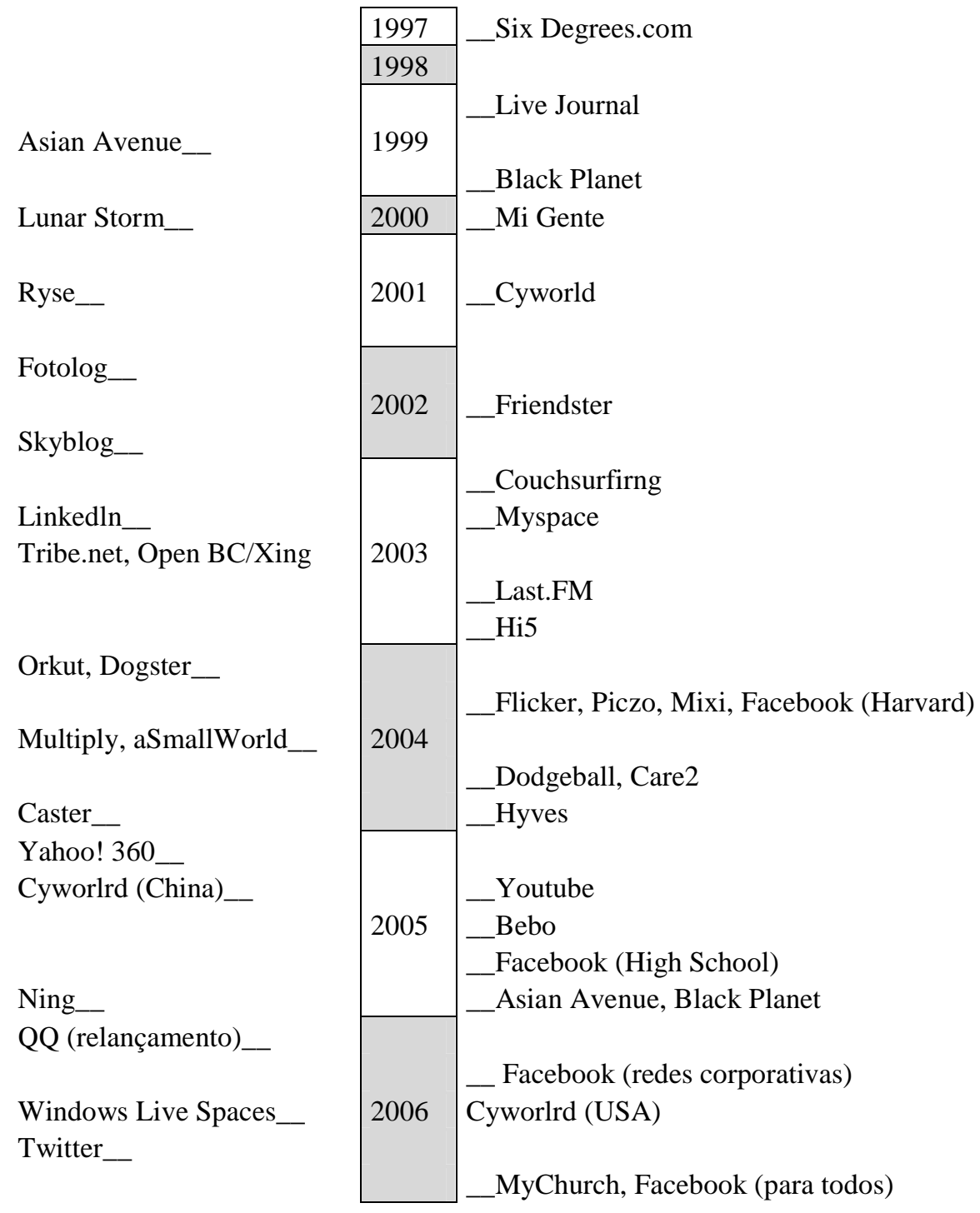

Figura 01 - Linha do Tempo das Principais Redes Sociais Virtuais

Fonte: Adaptação dos autores a partir de Boyd e Ellinson, (2008, p. 212).

Conforme aponta Packer (2011), muitas empresas têm utilizado as redes sociais para divulgar seus produtos, serviços e sustentar ou construir sua reputação. Esses mecanismos e ferramentas em que se usam as redes sociais para criar, discutir e dividir conteúdos, divulgando informações sobre produtos, serviços ou marcas são classificados como 'Mídias Sociais' (Dong-Hun, 2010; Packer, 2011; Kiezmann, Hermkens \& McCarthy, 2011) e este conceito é apresentado a seguir com o objetivo de demarcar os conceitos e fazer a diferenciação entre redes sociais e mídias sociais. 


\section{$3 \quad$ Metodologia}

Por se tratar de uma temática recente e ainda com algumas lacunas de conhecimento, o estudo necessitou de duas etapas: uma etapa qualitativa e outra quantitativa. A etapa qualitativa, de caráter exploratório teve como objetivo identificar possíveis brasileiros famosos que pudessem influenciar os usuários de redes sociais virtuais. Já a etapa quantitativa teve como objetivo buscar relações de causa-efeito entre variáveis demográficas e o boicote dos consumidores que usam as redes sociais virtuais. As duas fases são descritas detalhadamente a seguir.

\subsection{Fase Qualitativa}

A primeira fase da pesquisa, que se caracteriza por uma fase exploratória, envolveu dois estudantes de graduação para coletar dados primários junto a 100 usuários de redes sociais virtuais em uma universidade federal no estado do Rio de Janeiro. Cada usuário deveria listar cinco pessoas famosas que poderiam influenciá-lo a deixar de comprar um produto ou serviço. A seleção dos sujeitos foi por conveniência, levando-se em consideração o lócus dos pesquisadores (Seropédica - RJ) e teve como objetivo listar as principais pessoas famosas no Brasil que poderiam influenciar o entrevistado a deixar de comprar um produto ou serviço mediante discurso escrito ou falado daquelas pessoas em algum meio de comunicação.

$\mathrm{Na}$ entrevista pessoal com o respondente, os entrevistadores anotavam o nome das cinco pessoas famosas que, de acordo com o respondente, poderia influenciá-lo a deixar de comprar um produto/serviço. Na primeira contagem dos votos aparecem 162 pessoas famosas. Como este número ainda era alto, optou-se por realizar um corte de nomes para que fosse reduzido o número de opções de escolha para a fase seguinte (a elaboração do ques- tionário). Levando-se em consideração que apenas uma indicação poderia ser algo muito específico para um determinado respondente, foram escolhidas pessoas famosas que possuíam dois ou mais votos e descartadas aquelas que foram citadas apenas uma vez. Assim, ficaram 62 pessoas famosas.

Um pré-teste com 46 usuários de redes sociais virtuais foi realizado, sendo que de 46 respostas apenas 37 foram utilizadas, pois nove destas respostas estavam incompletas (sendo estas descartadas). $\mathrm{O}$ questionário foi construído numa plataforma online e os links foram distribuídos via rede social virtual Facebook. A principal contribuição do pré-teste foi verificar a interface do questionário com os usuários, evidenciando algumas dificuldades dos respondentes principalmente em relação à ordenação das respostas para as 10 personalidades mais influentes. O feedback de sete usuários que responderam o pré-teste evidenciou que estes tiveram dúvidas em relação à ordenação, uma vez que para eles a pessoa famosa mais importante deveria receber nota 10 e não nota 1 . Mediante estas constatações e sugestões dos respondentes fez-se uma nova ordenação e que se considerou a nota 10 para o mais influente, a nota 9 para o segundo mais influente e assim sucessivamente até chegar ao décimo indicado com a nota 1 . Após o pré-teste e as modificações emergidas deste processo, a base de dados foi apagada e iniciou-se o processo de coleta de dados.

\section{a. 3.2 Fase Quantitativa}

\section{Coleta e Tratamento dos Dados}

O questionário na plataforma Survey Monkey ficou disponível durante 32 dias para que os usuários de redes sociais pudessem preenchê-lo. Houve um processo de divulgação aleatória entre os usuários de redes sociais virtuais vinculados aos perfis dos autores deste artigo e também 
em páginas de grupos, como grupos da universidade que os autores trabalham e estudam. Durante 32 dias foram preenchidos 455 questionários.

$\mathrm{O}$ número relativamente baixo de observações se dá por dois motivos específicos. O primeiro deles se relaciona à extensão do questionário. Apresentar 62 nomes de pessoas famosas pode ter desestimulado os respondentes que não tinham uma recompensa por isso a continuar preenchendo-os (não foi oferecido nenhum tipo de brinde ao respondente para que ele completasse o questionário, o que fez com que o respondente não preenchesse correta e integralmente $\mathrm{o}$ instrumento de coleta de dados). O segundo motivo para uma amostra de apenas 272 observações diz respeito ao tratamento dos dados. Por ser uma amostra não-probabilística por conveniência, verificou-se que as observações concentraram-se entre universitários, graduados e pós-graduados, tendo poucos alunos de Ensino Médio ou Ensino Fundamental respondendo os questionários - especificamente 20 respondentes demonstrando pouca consistência e robustez estatística.
Ainda na fase de tratamento dos dados foram excluídas 183 observações. Dois critérios foram utilizados. $\mathrm{O}$ primeiro foi em relação às pessoas que entravam no link do questionário, iniciavam o preenchimento e não completavam. $\mathrm{O}$ segundo critério foi a escolha de trabalhar somente com estudantes e egressos da graduação e pós-graduação, o que justifica a exclusão de estudantes do Ensino Fundamental e Médio.

\section{Procedimentos Estatísticos}

Para a criação de dois rankings (pessoas famosas com maior influência no boicote e importância dos veículos de comunicação) foi utilizada a estatística descritiva. Além disso, conforme pode ser observado no Quadro 01, as 62 personalidades foram classificadas em oito grupos, conforme a veiculação de sua imagem na mídia. Para esta classificação contou-se com o auxílio de dois profissionais da área de Comunicação que classificaram as pessoas famosas de acordo com a sua atuação. Os grupos e os seus respectivos detalhes podem ser aprofundados a seguir.

Quadro 01: Classificação das Pessoas Famosas em Grupos de Acordo com a veiculação de suas imagens na mídia brasileira.

\begin{tabular}{|c|c|c|}
\hline GRUPO & PESSOAS FAMOSAS & $\begin{array}{c}\text { CARACTERÍSTICAS DOS PROFIS- } \\
\text { SIONAIS }\end{array}$ \\
\hline Jornalistas & $\begin{array}{l}\text { Ana Paula Padrão, Arnaldo Jabor, Bóris Ca- } \\
\text { soy, Fátima Bernardes, Gloria Maria, Patrícia } \\
\text { Poeta, Pedro Andrade, Pedro Bial, Sandra } \\
\text { Annenberg, Willian Bonner e Zeca Camargo. }\end{array}$ & $\begin{array}{c}\text { Profissionais que estão envolvidos com a } \\
\text { apresentação de telejornais ou programas } \\
\text { jornalísticos. }\end{array}$ \\
\hline Entretenimento & $\begin{array}{c}\text { Ana Maria Braga, Angélica, Danilo Gentilli, } \\
\text { Faustão, Jô Soares, Luciano Huck, Marcelo } \\
\text { Tas, Marco Luque, Marília Gabriela, Rafinha } \\
\text { Bastos, Sabrina Sato, Sílvio Santos, Xuxa e } \\
\text { Zeca Camargo. }\end{array}$ & $\begin{array}{l}\text { Profissionais que estão envolvidos com } \\
\text { programas de entretenimento (humor, culi- } \\
\text { nária ou reallity shows). Foram desconside- } \\
\text { rados profissionais de programas jornalísti- } \\
\text { cos. }\end{array}$ \\
\hline Religiosos & $\begin{array}{c}\text { Aline Barros, Cid Moreira, Francisco Silva } \\
\text { (Rede Melodia), Padre Marcelo Rossi e Silas } \\
\text { Malafaia. }\end{array}$ & $\begin{array}{c}\text { Pessoas que se destacam na mídia pela } \\
\text { relação que têm com a religião, indiferente } \\
\text { de qual religião sejam. }\end{array}$ \\
\hline Atletas & $\begin{array}{l}\text { Anderson Silva, Bernardinho, Juninho Per- } \\
\text { nambucano, Kaká, Romário, Ronaldinho, } \\
\text { Gaúcho, Ronaldo Fenômeno e Thiago Neves. }\end{array}$ & $\begin{array}{l}\text { Profissionais que têm ou tiveram alguma } \\
\text { relação com o esporte, como, por exemplo, } \\
\text { atuais e ex-jogadores, técnicos ou dirigen- } \\
\text { tes de entidades esportivas. }\end{array}$ \\
\hline
\end{tabular}




\begin{tabular}{|c|c|c|}
\hline Atores & $\begin{array}{c}\text { Antônio Fagundes, Marcos Palmeira, Selton } \\
\text { Mello, Tony Ramos e Wagner Moura. }\end{array}$ & $\begin{array}{l}\text { Profissionais reconhecidos pelos seus tra- } \\
\text { balhos na TV, Rádio ou Teatro. }\end{array}$ \\
\hline Cantores & $\begin{array}{c}\text { Chico Buarque, Cláudia Leite, Elba Ramalho, } \\
\text { Hebert Viana, Ivete Sangalo, Jorge e Mateus, } \\
\text { Sandy e Zeca Baleiro. }\end{array}$ & $\begin{array}{l}\text { Profissionais que têm como profissão a } \\
\text { música. }\end{array}$ \\
\hline Políticos & $\begin{array}{l}\text { Dilma Rousseff, Lula, Marcelo Freixo, Marina } \\
\text { Silva, Plínio (ex-candidato a presidência), }\end{array}$ & $\begin{array}{c}\text { Pessoas que estão ou estiveram envolvidas } \\
\text { no cenário político brasileiro. }\end{array}$ \\
\hline Personalidades & $\begin{array}{l}\text { Dr. Dráuzio Varela, Eike Batista, Felipe Neto, } \\
\text { Gisele Bündchen, João Dória, Miriam Leitão e } \\
\text { Roberto Justus. }\end{array}$ & $\begin{array}{l}\text { Todas as pessoas famosas que não se en- } \\
\text { caixaram em um dos sete grupos anteriores } \\
\text { foram classificadas neste grupo. Caracterís- } \\
\text { ticas como reconhecimento técnico de um } \\
\text { profissional em determinada área, riqueza } \\
\text { ou tradição familiar foram considerados } \\
\text { aqui. }\end{array}$ \\
\hline
\end{tabular}

Fonte: Elaboração dos autores

Após a classificação descrita no quadro anterior, foi calculada a média de cada grupo formado pelas 62 pessoas famosas. Em outras palavras, transformou-se 62 variáveis em apenas oito variáveis agregadas. Uma vez calculadas as médias das oito variáveis criadas, foi realizada uma análise de correlação entre estes oito grupos. A Análise de Correlação, segundo Bussab e Moretin (1987, p. 288) “(...) é adequada para testar o nível de associação entre duas variáveis quantitativas". O nível de significância utilizado para o Teste de Hipótese de Correlação neste estudo foi de $\mathrm{p} \leq 0,1$. Os resultados são descritos na próxima seção.

\section{Resultados e Discussão}

Os resultados apresentados neste item são provenientes da pesquisa de campo realizada com os sujeitos descritos anteriormente (consumidores que são usuários de redes sociais virtuais). A Tabela 01 apresenta a colocação das pessoas que estão presentes na mídia e que podem influ- enciar os usuários de redes sociais a deixarem de comprar produtos ou serviços de uma empresa mediante o discurso de uma dessas personalidades.

A estatística descritiva que dá origem à Tabela 01 apresenta tanto o número de vezes que a pessoa famosa foi citada (número de pessoas) quanto à pontuação absoluta que foi calculada a partir da soma dos valores absolutos obtidos pela pessoa famosa no final da pesquisa. O critério para construção do ranking foi a pontuação absoluta. Assim, O Dr. Dráuzio Varela foi à pessoa famosa com maior influência de boicote na amostra analisada, sendo aquele que mais foi lembrado pelos entrevistados (111 respondentes o citaram) e o que totalizou o maior score final (679). Talvez, o Dr. Dráuzio Varela seja o primeiro colocado pelo fato de ser um médico reconhecido pela suas dicas de saúde em programas importantes como o Fantástico (programa este em que o médico apresentou um reallity show sobre os problemas do Tabagismo no ano de 2011). 
Tabela 01: Ranking dos 10 famosos que mais influenciam o boicote na percepção de consumidores usuários de redes sociais virtuais

\begin{tabular}{cccc}
\hline COLOCAÇÃO & FAMOSO (A) & $\begin{array}{c}\text { NÚMERO DE } \\
\text { PESSOAS }\end{array}$ & $\begin{array}{c}\text { PONTUAÇÃO } \\
\text { ABSOLUTA }\end{array}$ \\
\hline $\mathbf{1}^{\mathbf{0}}$ & Dr. Dráuzio Varela & 111 & 679 \\
$\mathbf{2}^{\mathbf{o}}$ & Eike Batista & 111 & 664 \\
$\mathbf{3}^{\mathbf{0}}$ & Jô Soares & 109 & 645 \\
$\mathbf{4}^{\mathbf{0}}$ & Willian Bonner & 104 & 612 \\
$\mathbf{5}^{\mathbf{0}}$ & Chico Buarque & 97 & 593 \\
$\mathbf{6}^{\mathbf{0}}$ & Arnaldo Jabor & 96 & 576 \\
$\mathbf{7}^{\mathbf{0}}$ & Luciano Huck & 95 & 557 \\
$\mathbf{8}^{\mathbf{0}}$ & Fátima Bernardes & 93 & 498 \\
$\mathbf{9}^{\mathbf{0}}$ & Dilma Rousseff & 85 & 487 \\
$\mathbf{1 0}^{\mathbf{o}}$ & Lula & 84 & 459 \\
\hline
\end{tabular}

Fonte: Dados da Pesquisa.

Toda relação dos 62 nomes e a posição das pessoas famosas no ranking pode ser verificada no Anexo, presente no final desse artigo. Dos 10 primeiros nomes que aparecem na lista de pessoas famosas que influenciam o consumidor no boicote, apenas quatro não estão ligados à Rede Globo de Televisão (dois políticos, um cantor e um empresário). Conforme pode ser verifi- cado na Tabela 02, a TV aparece como o segundo veículo mais importante para o consumidor que participou desta pesquisa o que pode justificar a presença de seis pessoas famosas ligadas no Top 10 do ranking. Como o grupo de consumidores foi composto por usuários de redes sociais virtuais, faz sentido que o veículo mais utilização pelo grupo seja a Internet.

Tabela 02 - Ranking de Importância dos Meios de Comunicação para os respondentes

\begin{tabular}{ccc}
\hline MEIO DE COMUNICAÇÃO & $\begin{array}{c}\text { RANKING DE IMPOR- } \\
\text { TÂNCIA }\end{array}$ & MÉDIA \\
\hline Internet (sites, Facebook, Twitter ou & 1 & 4,12 \\
Orkut) & & 3,53 \\
TV & 2 & 3,15 \\
Jornais impressos & 3 & 2,42 \\
Panfletos e/ou outdoor & 4 & 1,78 \\
Rádio & 5 & \\
\hline
\end{tabular}

Fonte: Dados da Pesquisa.

Um dos objetivos da pesquisa foi identificar a existência de correlação entre os grupos de pessoas famosas classificadas na pesquisa. Teve-se como pressuposto que alguns grupos poderiam estar correlacionados positivamente, como pro exem- 
plo, Ator e Entretenimento. Mas, o que os resultados evidenciam na Tabela 03 é que este pressuposto de correlação positiva não existiu para nenhum grupo. O que pode ser analisado na Tabela 03 é a correlação negativa entre alguns grupos. Em cada grupo foi analisada a sua respectiva média, ou seja, a soma de todas as observações do grupo e sua divisão a partir do número de observações.

Tabela 03- Correlações entre os Grupos

\begin{tabular}{|c|c|c|c|c|c|c|c|c|c|}
\hline & & Mreligio & Mentrete & Mjornal & Matleta & Mator & $\begin{array}{l}\text { Mcan- } \\
\text { tor }\end{array}$ & Mpolit & Mperson \\
\hline \multirow{3}{*}{ Mreligio } & Correlação & 1 &,$- 245^{*}$ &,$- 389^{* *}$ &,- 087 &,- 311 &,$- 350^{*}$ & ,073 &,- 164 \\
\hline & Sig. (2-tailed) & & , 029 &, 000 & ,530 & ,078 & ,014 & ,617 &, 175 \\
\hline & $\mathrm{N}$ & 92 & 79 & 84 & 54 & 33 & 49 & 50 & 70 \\
\hline \multirow{3}{*}{ Mentrete } & Correlação &,$- 245^{*}$ & 1 &,$- 215^{* *}$ &,$- 206^{*}$ & 025 &,$- 342^{* *}$ &,$- 204^{*}$ &,$- 152^{*}$ \\
\hline & Sig. (2-tailed) & ,029 & & ,002 &, 035 & ,781 & ,000 & 020 & ,037 \\
\hline & $\mathrm{N}$ & 79 & 246 & 213 & 105 & 122 & 158 & 130 & 189 \\
\hline \multirow{3}{*}{ Mjornal } & Correlação &,$- 389^{* *}$ &,$- 215^{* *}$ & 1 &,$- 204^{*}$ &,- 016 &,- 113 &,$- 299^{* * *}$ &,$- 166^{*}$ \\
\hline & Sig. (2-tailed) & ,000 & ,002 & & 046 & ,866 & 185 & ,001 & ,027 \\
\hline & $\mathrm{N}$ & 84 & 213 & 231 & 96 & 109 & 139 & 116 & 178 \\
\hline \multirow{3}{*}{ Matleta } & Correlação &,- 087 &,$- 206^{*}$ &,$- 204^{*}$ & 1 &,- 055 & ,029 &,- 227 & ,007 \\
\hline & Sig. (2-tailed) & ,530 &, 035 & 046 & & ,708 & ,812 &, 105 & ,948 \\
\hline & $\mathrm{N}$ & 54 & 105 & 96 & 114 & 48 & 72 & 52 & 79 \\
\hline \multirow{3}{*}{ Mator } & Correlação &,- 311 & 025 &,- 016 &,- 055 & 1 &,$- 287^{* *}$ &,$- 229^{*}$ &,$- 440^{* * *}$ \\
\hline & Sig. (2-tailed) & ,078 & ,781 & ,866 & ,708 & & ,006 & 048 & $\overline{, 000}$ \\
\hline & $\mathrm{N}$ & 33 & 122 & 109 & 48 & 132 & 92 & 75 & 98 \\
\hline \multirow{3}{*}{ Mcantor } & Correlação &,$- 350^{*}$ &,$- 342^{* *}$ &,- 113 & ,029 &,$- 287^{* *}$ & 1 &,- 166 &,- 022 \\
\hline & Sig. (2-tailed) & ,014 & , 000 & , 185 & ,812 & ,006 & & , 102 & 8,810 \\
\hline & $\mathrm{N}$ & 49 & 158 & 139 & 72 & 92 & 172 & 99 & 126 \\
\hline \multirow{3}{*}{ Mpolit } & Correlação & ,073 &,$- 204^{*}$ &,$- 299^{* *}$ &,- 227 &,$- 229^{*}$ &,- 166 & 1 &,$- 209^{*}$ \\
\hline & Sig. (2-tailed) & ,617 & ,020 & ,001 & 105 & ,048 & 102 & & ,025 \\
\hline & $\mathrm{N}$ & 50 & 130 & 116 & 52 & 75 & 99 & 149 & 115 \\
\hline \multirow{3}{*}{ Mperson } & Correlação &,- 164 &,$- 152^{*}$ &,$- 166^{*}$ & ,007 &,$- 440^{* *}$ &,- 022 &,$- 209^{*}$ & 1 \\
\hline & Sig. (2-tailed) & , 175 & ,037 & ,027 & ,948 & ,000 & ,810 & ,025 & \\
\hline & $\mathrm{N}$ & 70 & 189 & 178 & 79 & 98 & 126 & 115 & 210 \\
\hline
\end{tabular}

$* \mathrm{p} \leq 0,1$

$* * \mathrm{p} \leq 0,05$

Fonte: Cruzamento dos dados da pesquisa.

A correlação entre os "Religiosos" e outros grupos, como "Entretenimento", "Jornalismo", "Ator" e "Cantor", apresentou uma correlação significativa e negativa. Esse resultado permite entender que enquanto um consumidor da amostra analisada recebe influência de religiosos famosos, provavelmente este consumidor não receberá influência de artistas ligados ao entretenimento, jornalistas ou cantores. A possível explicação para este resultado pode residir na questão da moral religiosa. A Moral como um mecanismo que dá orientações e que regula o certo e o errado dentro da sociedade (ASHLEY, 2005), neste caso uma sociedade religiosa Cristã, algumas vezes doutrina os seguidores para que eles entendam como certo aquilo que 
está na Bíblia, onde qualquer desvio mínimo daquilo que está na doutrina de uma igreja ou na Bíblia pode ser considerado como errado para o consumidor que aponta religiosos famosos como pessoas que podem influenciá-lo a boicotar. A função do jornalista é questionar e, às vezes, discutir dogmas.

Cantores levam alegria de maneira muitas vezes irreverente ao seu público. A atuação de cantores e jornalistas, por exemplo, podem ir contra os pensamentos ortodoxos de religiosos. Religiosos famosos como influentes no boicote na perspectiva dos consumidores da amostra podem ter visões de mundo diferentes e mais ortodoxas que jornalistas, cantores e artistas de entretenimento, o que pode explicar a correlação negativa entre esses grupos.

Após apresentar as correlações negativas entre os grupos estabelecidos para este estudo, as variáveis demográficas (sexo, escolaridade, religião e renda) também foram analisadas e cruzadas com a variável influência do artista no boicote. $\mathrm{O}$ primeiro resultado que pode ser verificado na Tabela 04, demonstra que em relação ao gênero, $51,5 \%$ tanto de homens quanto mulheres são indiferentes ao discurso de uma pessoa famosa para influenciar este consumidor a boicotar. Entretanto, 48,5\% concordam ou concordam totalmente que as pessoas que eles atribuíram notas de 10 a 01 influenciam no boicote. Assim, não se pode afirmar que foi encontrada uma diferença de gênero neste estudo. Logo, com os resultados empíricos desta amostra não se pode dizer que mulheres estão mais propensas ao boicote como já evidenciou estudos como o de Klein, Smith \& John (2004), Nielson (2010) \& Stolle et al (2005).

Tabela 04 - Cruzamento da variável Sexo com Influência da Pessoa Famosa no Boicote

\begin{tabular}{ccccc}
\hline \multirow{2}{*}{ SEXO } & \multicolumn{2}{c}{ INFLUENCIA DE UMA PESSOA FAMOSA NO BOICO- } & TOTAL \\
\cline { 2 - 4 } & Indiferente & Concordo & $\begin{array}{c}\text { Concordo totalmen- } \\
\text { te }\end{array}$ & \\
\cline { 2 - 4 } Feminino & $51,5 \%$ & $42,0 \%$ & $6,5 \%$ & $100,0 \%$ \\
Masculino & $51,5 \%$ & $37,4 \%$ & $11,1 \%$ & $100,0 \%$ \\
TOTAL & $51,5 \%$ & $40,3 \%$ & $8,2 \%$ & $100,0 \%$ \\
\hline
\end{tabular}

Fonte: Cruzamento dos dados da pesquisa.

No que diz respeito à Escolaridade, as pessoas com graduação completa foram aquelas que se mostraram mais influenciadas pelas pessoas famosas, uma vez que aproximadamente apenas $38 \%$ se mostraram indiferentes à influência dos artistas. Isso demonstra que no lócus das redes sociais virtuais, graduados seguidos de pessoas com cursos de pós-graduação completa têm um posicionamento mais extremo e recebem maior influência de artistas no boicote que alunos que cursam graduação ou aqueles que ainda cursam um curso de pós-graduação. A Tabela 05 apresenta estas informações.

Nielson (2010) verificou que existe uma correlação positiva e significativa $(\mathrm{p}<$ $0,001)$ entre o nível educacional e o boicote dos consumidores e quando se analisa a indiferença ao boicote, o grupo que apresentou menor score foi o de consumidores com pós-graduação completa. Ou seja, consumidores com maior nível educacional, nesta amostra, se mostraram mais influenciados que os demais grupos quando se analisa o percentual de indiferença. 
Tabela 05 - Cruzamento da variável Escolaridade com Influência da Pessoa Famosa no Boicote

\begin{tabular}{|c|c|c|c|c|}
\hline \multirow[t]{2}{*}{ ESCOLARIDADE } & \multicolumn{3}{|c|}{$\begin{array}{l}\text { INFLUÊNCIA DE UMA PESSOA FAMOSA NO } \\
\text { BOICOTE }\end{array}$} & \multirow[t]{2}{*}{ TOTAL } \\
\hline & Indiferente & Concordo & $\begin{array}{c}\text { Concordo totalmen- } \\
\text { te }\end{array}$ & \\
\hline $\begin{array}{l}\text { Ensino Superior (cursan- } \\
\text { do) }\end{array}$ & $55,9 \%$ & $38,2 \%$ & $5,9 \%$ & $100,0 \%$ \\
\hline $\begin{array}{c}\text { Ensino Superior Comple- } \\
\text { to }\end{array}$ & $38,9 \%$ & $47,2 \%$ & $13,9 \%$ & $100,0 \%$ \\
\hline $\begin{array}{c}\text { Pós-Graduação (cursan- } \\
\text { do) }\end{array}$ & $52,4 \%$ & $28,6 \%$ & $19,0 \%$ & $100,0 \%$ \\
\hline Pós-Graduação Completa & $47,5 \%$ & $45,8 \%$ & $6,8 \%$ & $100,0 \%$ \\
\hline TOTAL & $51,5 \%$ & $40,3 \%$ & $8,2 \%$ & $100,0 \%$ \\
\hline
\end{tabular}

Fonte: Cruzamento dos dados da pesquisa.

Quando se analisa a questão da religião e a divisão das religiões no Brasil, algumas análises surgem dos resultados apresentados na Tabela 06. Por exemplo, a pessoa que se classifica como Ateu é indiferente ao boicote, pois $73,1 \%$ dos Ateus não deram importância à influência das pessoas famosas em sua decisão de boicote, o que faz com que este grupo destoe da média total $(51,5 \%)$ e das médias dos outros grupos. Talvez, o Ateu seja uma pessoa mais crítica e menos influenciada que os demais religiosos que acreditam em dogmas.

Em uma pesquisa realizada por Novaes (2004) com jovens brasileiros em relação à espiritualidade, os que se classificaram como ateus não estavam entre os mais po- bres e também nem entre os com pouco nível educacional quando comparados. Um ensaio teórico sobre o Neoateísmo escrito por Paine (2010) pode ajudar a entender o comportamento em relação ao boicote tanto de cristãos como de ateus. Para o autor, o fiel religioso é crente nas verdades e dogmas da sua religião. Já o ateu, é esclarecido e emancipado como "homem científico que duvida, analisa, pondera e chega a conclusões com a maior circunspeção e cuidado" (Paine, 2010, p. 15). Isso contribui na análise da influência das pessoas famosas no boicote para os dois grupos: religiosos e ateu, sendo o ateu mais difícil de ser convencido. 
Tabela 06 - Cruzamento da variável Religião com Influência da Pessoa Famosa no Boicote

\begin{tabular}{|c|c|c|c|c|}
\hline \multirow[t]{2}{*}{ RELIGIÃO } & \multicolumn{3}{|c|}{$\begin{array}{l}\text { INFLUENCIA DE UMA PESSOA FAMOSA NO BOI- } \\
\text { COTE }\end{array}$} & \multirow[t]{2}{*}{ TOTAL } \\
\hline & Indiferente & Concordo & Concordo totalmente & \\
\hline Ateu & $73,1 \%$ & $26,9 \%$ & $0 \%$ & $100,0 \%$ \\
\hline Espírita & $52,4 \%$ & $42,9 \%$ & $4,8 \%$ & $100,0 \%$ \\
\hline Agnóstico & $52,8 \%$ & $36,1 \%$ & $11,1 \%$ & $100,0 \%$ \\
\hline $\begin{array}{l}\text { Cristã Católi- } \\
\text { ca }\end{array}$ & $43,4 \%$ & $47,0 \%$ & $9,6 \%$ & $100,0 \%$ \\
\hline Outras & $58,1 \%$ & $35,5 \%$ & $6,5 \%$ & $100,0 \%$ \\
\hline $\begin{array}{l}\text { Cristã Evan- } \\
\text { gélica Pente- } \\
\text { costal }\end{array}$ & $44,4 \%$ & $44,4 \%$ & $11,1 \%$ & $100,0 \%$ \\
\hline $\begin{array}{l}\text { Cristã Evan- } \\
\text { gélica Ortodo- } \\
\text { xa }\end{array}$ & $57,1 \%$ & $28,6 \%$ & $14,3 \%$ & $100,0 \%$ \\
\hline TOTAL & $51,5 \%$ & $40,3 \%$ & $8,2 \%$ & $100,0 \%$ \\
\hline
\end{tabular}

Fonte: Cruzamento dos dados da pesquisa

Enquanto o total de pessoas da amostra que concorda totalmente com o boicote é de $8,2 \%$, quando se olha somente os consumidores que se classificaram como Cristãos Evangélicos Ortodoxos, esse percentual sobe para $14,3 \%$ (quase o dobro). Por outro lado, o grupo de consumidores que se classificaram como Católicos ou Pentecostais usuários de redes sociais virtuais não são indiferentes à influência de pessoas famosas no boicote, pois eles tendem a concordar ou concordar totalmente com a influência de pessoas famosas na sua decisão em boicotar um produto ou serviço, o que ajuda a evidenciar o impacto da religião no boicote. Esse resultado empírico apenas destaca a influência da religião no boicote e corrobora na classificação de Friedman (1999) que já havia discutido o boicote religioso como um tipo de boicote.
Em relação à Renda, o cruzamento dos dados mostra uma situação interessante: pobres e ricos tem um comportamento semelhante em relação à influência de pessoas famosas na sua decisão de boicotar. Como pode ser verificado na Tabela 07, enquanto à média daqueles que são indiferentes a boicote é $51,7 \%$, os pobres tiveram praticamente o mesmo comportamento da média geral $(51,5 \%)$ e os ricos tiveram um comportamento próximo $(53,6 \%)$. Foi a classe média alta que se mostrou mais influenciada pelos artistas com $63,1 \%$, sendo que essa classe destoou em relação à média total da amostra em relação àqueles indivíduos que concordam totalmente com a influência de pessoas famosas. Ou seja, os dados evidenciam neste contexto que a classe média alta é a classe mais influenciada pelas pessoas famosas no que diz respeito ao boicote. 
Tabela 07 - Cruzamento da variável Renda com Influência da Pessoa Famosa no Boicote

\begin{tabular}{|c|c|c|c|c|}
\hline \multirow[b]{2}{*}{ RENDA } & \multicolumn{3}{|c|}{$\begin{array}{l}\text { INFLUENNCIA DE UMA PESSOA } \\
\text { FAMOSA NO BOICOTE }\end{array}$} & \multirow[t]{2}{*}{ TOTAL } \\
\hline & Indiferente & Concordo & $\begin{array}{l}\text { Concordo } \\
\text { totalmente }\end{array}$ & \\
\hline Até um salário mínimo ( $\mathrm{R} \$ 622,00)$ & $71,4 \%$ & $28,6 \%$ & $0 \%$ & $100,0 \%$ \\
\hline Até dois salários mínimos ( $\mathrm{R} \$ 1244,00)$ & $51,5 \%$ & $39,4 \%$ & $9,1 \%$ & $100,0 \%$ \\
\hline Até três salários mínimos $(\mathrm{R} \$ \mathbf{1 8 6 6 , 0 0})$ & $55,8 \%$ & $41,9 \%$ & $2,3 \%$ & $100,0 \%$ \\
\hline Até cinco salários mínimos $(\mathbf{R} \$ \mathbf{3 1 1 0 , 0 0})$ & $51,9 \%$ & $40,7 \%$ & $7,4 \%$ & $100,0 \%$ \\
\hline $\begin{array}{c}\text { Entre } 5 \text { e } 10 \text { salários mínimos (Entre R\$ } \\
\text { 3110,01 até } R \$ 6220,00)\end{array}$ & $45,9 \%$ & $39,2 \%$ & $14,9 \%$ & $100,0 \%$ \\
\hline $\begin{array}{l}\text { Mais que } 10 \text { salários mínimos (mais de } \mathrm{R} \$ \\
\qquad 6220,00 \text { ) }\end{array}$ & $53,6 \%$ & $41,1 \%$ & $5,4 \%$ & $100,0 \%$ \\
\hline TOTAL & $51,7 \%$ & $40,1 \%$ & $8,2 \%$ & $100,0 \%$ \\
\hline
\end{tabular}

Fonte: Cruzamento dos dados da pesquisa.

\section{5}

Implicações Teóricas e Gerenci-
ais, Limitações do Método e Su-
gestões para Futuras Pesquisas

O objetivo deste estudo foi verificar quais pessoas famosas influenciam consumidores usuários de redes sociais virtuais a boicotarem um produto, serviço ou empresa. Como resultado, nas três primeiras posições, verificou-se que este grupo de consumidores analisado nesta amostra se mostrou influenciado principalmente pelo médico Dráuzio Varella, pelo empresário Eike Batista e pelo apresentador Jô Soares. As únicas mulheres famosas que aparecem entre os 10 primeiros colocados e que podem influenciar o consumidor a boicotar foram Fátima Bernardes ( $8^{\circ}$ lugar) e Dilma Rousseff $\left(9^{\circ}\right.$ lugar). A Internet apareceu como principal meio de informação para o consumidor usuário de redes sociais e, a $\mathrm{TV}$, em segundo lugar - o que pode explicar a presença de seis artistas da Rede Globo nas 10 primeiras posições do ranking. Embora a TV tenha aparecido em segundo lugar, o veículo de comunicação é o grande responsável pela disseminação de informações no extenso território brasileiro.
Entretanto, entendeu-se que apresentar somente o ranking das pessoas famosas por meio de estatística descritiva, embora fosse uma contribuição, não se teria contribuições teóricas e sugestões para futuras pesquisas, o que motivou a criação dos grupos de pessoas famosas e a análise de suas correlações. E, da análise das correlações, o que foi verificado é que nenhum dos grupos apresentou correlação significativa e positiva entre eles. As correlações foram significativas, porém, negativas, o que permite entender que o consumidor que recebe influência de um grupo provavelmente não receberá de outro grupo.

$\mathrm{O}$ presente estudo apresenta algumas limitações, embora tais limitações não o façam menos importante ou relevante. A primeira limitação foi a escolha dos sujeitos da pesquisa na primeira fase pelos entrevistados. Por exemplo, Marcelo Freixo, Thiago Neves, Ronaldinho Gaúcho e Juninho Pernambucano poderiam não aparecer na listagem final caso a sugestão de pessoas famosas na primeira etapa fosse feita em Minas Gerais, São Paulo ou Rio Grande do Sul. Outras limitações estão relacionadas à amostra trabalhada: tamanho da amostra e generalização. De 455 respondentes, ape- 
nas 272 fizeram parte da análise de dados. Assim, com o volume de usuários de redes sociais virtuais, não se pode supor que os resultados aqui apresentados representam a realidade como um todo.

Apesar das limitações, o trabalho apresenta contribuições teóricas e gerenciais. Em relação às contribuições teóricas, os dados empíricos suscitam reflexões sobre a influência de pessoas famosas no Brasil e comportamento do consumidor em relação ao boicote. Klein, Smith \& John (2004) verificaram a influência de parentes e amigos no boicote. $\mathrm{O}$ presente estudo verificou a influência de pessoas presentes na mídia no país, sendo essa uma contribuição simples, porém, importante para a grande lacuna de conhecimento existente no tema boicote de consumidores. A segunda contribuição teórica que pode derivar dos dados aqui analisados é discutir a questão da religião e boicote. Friedman (1999) classificou alguns tipos de boicotes, dentre eles o boicote religioso. $\mathrm{O}$ presente estudo com base na amostra sugere que os consumidores que se classificaram como Ateus são indiferentes à influência de pessoas famosas no boicote, enquanto Cristãos (evangélicos ou católicos) se mostraram mais influenciados que os primeiros. A terceira contribuição é o lócus da pesquisa: as redes sociais virtuais. Alguns boicotes tomaram força nas redes sociais, como o caso da empresa brasileira Arezzo (Cruz, 2011b) e, entender o comportamento destes consumidores em relação ao boicote e às pessoas famosas pode ajudar suscitar novas questões na temática dos boicotes dos consumidores.

Além das contribuições teóricas, têmse as contribuições gerenciais: (a) gestores devem estar atentos às redes sociais virtuais como lócus de disseminação de informação em relação às suas próprias empresas, buscando gerenciar possíveis crises que podem afetar a imagem ou reputação dessas; (b) pessoas famosas no Brasil podem influenciar seus seguidores em redes sociais a deixar de comprar um produto ou serviço de uma empresa; (c) religião deve ser um tema a ser tratado com cuidado por uma empresa para evitar comportamento de boicote - vide caso da empresa Du Loren (Cruz, 2011b); e (d) alunos de pósgraduação podem ser futuros formadores de opinião dentro ou fora das redes sociais virtuais e entender seus comportamentos pode facilitar o gerenciamento de uma possível crise de reputação.

Como o estudo aqui realizado, além de relevante, suscita novas questões relacionadas à lacuna do boicote dos consumidores. Algumas dessas surgem e podem ser abordadas em futuras pesquisas, como: (i) Cristãos estão mais propensos ao boicote que Ateus?; (ii) usuários de redes sociais Cristãos estão mais propensos ao boicote que consumidores Cristãos que não utilizam redes sociais virtuais?; (iii) Por que ricos e pobres têm um comportamento semelhante e têm pouca influência de pessoas famosas no Brasil no que diz respeito ao boicote? Por que o grupo de Políticos possui correlação significativa negativa com Entretenimento? Essas e outras questões podem ser aprofundadas em outros estudos e demonstra a riqueza de possibilidades na temática do boicote dos consumidores.

\section{Referências}

AAKER, D. J. Leaveraging the corporate brand. California Management Review, vol. 46, n. 03, p. 06-18, 2004.

ALBUQUERQUE, F. M. de F.; NUNES, M. A. e PEREIRA, R. de C. de F. Retaliação e vingança de consumidores em comunidades virtuais anti-marcas. Anais do EnADI - Anpad. Anpad: Recife, 2009. 
ASHLEY, P. A. Ética e responsabilidade social nos negócios. São Paulo: Editora Saraiva, 2005.

BALESTRIN, A. e VARGAS, L. M. Evidências teóricas para a compreensão das redes interorganizacionais. In: Anais do EnEO 2002, Recife: Anpad, 2002.

BARDA, C. e SARDIANOU, E. Analysing consumers' 'activism' in response to rising prices.International Journal of Consumer Studies, 34, p. 133-139, 2010.

BOYD, D. M. e ELLISON, N. B. Social network sites: Definition, history, and scholarship. Journal of ComputerMediated Communication, 2008.

BUSSAB, W. de O. e MORETTIN, P. A. Estatística Básica. São Paulo: Atlas, 1987.

CRUZ, B. de P. A. Boicote de consumidores em relação à responsabilidade social corporativa. Anais do XXXV EnAnpad, 2011, Rio de Janeiro: Anpad, 2011 .

CRUZ, B. de P. A. Boicote de consumidores: demarcação de conceitos e casos no brasil. Anais do XVII Enangrad, 2011, São Paulo: ANGRAD, 2011 b.

CURRAS-PEREZ, R.; BIGNEALCANIZ, E.; e ALVARADOHERREIRA, A. The Role of selfdefinitional principles in consumer identification with a socially responsible company. Journal of Business Ethics, v. 89, p. 547-64, 2009.

DONG-HUN, L. Growing Popularity of Social Media and Business Strategy. Korean Consumer \& Society Serie Quartely, 2010.

FRIEDMAN, M. Consumer Boycotts - effecting change trough the marketplace and the media. New York: Routledge, 1999.
KLEIN, J. G.; SMITH, N. C. e JOHN, A. Why we boycott: Consumer motivations for boicott participation. Journal of Marketing, v. 68, p. 92-109, 2004.

LONGMAN DICTIONARY. Longman Dictionary of Contemporary Eng-

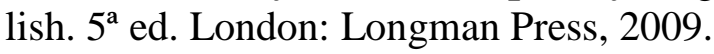

MARTELETO, R. M. Análise de redes sociais: aplicação nos estudos de transferência da informação. Revista Ciência da Informação, Brasília, v. 30, n. 1, jan./abr, 2001, p. 71-81.

MIZRUCHI, M. S. Análise de redes sociais: avanços recentes e controvérsias atuais. Revista de Administração de Empresas, v. 46, n. 3, 2006, p. 72-86.

MIZRUCHI, M. S. The structure of corporate political action: Interfirm relations and their consequences. Cambridge, MA: Harvard University Press, 1992.

NOVAES, R. Os "jovens sem religião": ventos secularizantes, "espírito de época" e novos sincretismos. Notas preliminares. Estudos Avançados, v. 18, n. 52, 2004. Disponível em: http://www.scielo.br/pdf/ea/v18n52/a20v1 852.pdf.

PAINE, S. R. Fundamentalismo ateu contra fundamentalismo religioso. Revista Horizonte, v. 8, n. 18, jul/set, 2010, p. 0926.

PALAZZO, G. e BASU, K.The ethical backlash of corporate branding. Journal of Business Ethics, v. 73, p. 333-346, 2007.

PACKER, R. Social Media Marketing: The art of conversational sales. We simplify the internet. Disponível em: $<$ http://wsiinstitute.com/media/ec/SocialM edia MarketingWhitepaper.pdf $>$. Acesso em: 3 de jan 2012. 
RIBEIRO, P. C. e OLIVEIRA, R. O impacto da ação das milícias em relação às políticas públicas de segurança no Rio de Janeiro. TNI Briefing Series, March/2010. Disponível em: http://dev.tni.org/sites/dev.tni.org/files/dow nload/crime4p.pdf. Acesso em 29 jan. 2012.

SCHERER-WARREN, I. Redes de movimentos sociais. São Paulo: Edições Loyola, 1993.

SMITH, N. C.; PALAZZO, G.; e BHATTACHARYA, C. B. Marketing consequences: Stakeholder marketing and supply chain corporate social responsibility issues. Business Ethics Quartely, p. 617641, (Oct - 2010), 2010.

SOULE, S. A. Contention and corporate social responsibility.Oxford: Cambridge University Press, 2009.

TOMAÉL, M. I.; ALCARÁ, A. R.; CHIARA, I. G. D.. Das redes sociais à inovação. Revista Ciência da Informação, Brasília, v.34, n.2, p.93 - 104, 2005. 
Influência de brasileiros famosos no boicote de consumidores que usam redes sociais virtuais

\section{Anexos}

Anexo 01- Ranking completo das pessoas famosas que participaram da pesquisa

\begin{tabular}{|c|c|c|}
\hline Posição & Pessoa Famosa & $\begin{array}{c}\text { Valor } \\
\text { Absoluto }\end{array}$ \\
\hline 1 & Dr. Dráuzio Varela & 679 \\
\hline 2 & Eike Batista & 664 \\
\hline 3 & Jô Soares & 645 \\
\hline 4 & Willian Bonner & 612 \\
\hline 5 & Chico Buarque & 593 \\
\hline 6 & Arnaldo Jabor & 576 \\
\hline 7 & Luciano Huck & 557 \\
\hline 8 & Fátima Bernardes & 498 \\
\hline 9 & Dilma Rousseff & 487 \\
\hline 10 & Lula & 459 \\
\hline 11 & Maria Gabriela & 456 \\
\hline 12 & Marcelo Tas & 403 \\
\hline 13 & Wágner Moura & 368 \\
\hline 14 & Selton Melo & 363 \\
\hline 15 & Marina Silva & 358 \\
\hline 16 & Danilo Gentilli & 351 \\
\hline 17 & Rafinha Bastos & 324 \\
\hline 18 & Roberto Justus & 319 \\
\hline 19 & Ana Maria Braga & 311 \\
\hline 20 & Gisele Bündchen & 310 \\
\hline 21 & Patrícia Poeta & 305 \\
\hline 22 & Ivete Sangalo & 302 \\
\hline 23 & Sandra Annenberg & 301 \\
\hline 24 & Ana Paula Padrão & 282 \\
\hline 25 & Herbert Viana & 280 \\
\hline 26 & Aline Barros & 260 \\
\hline 27 & Marcelo Freixo & 251 \\
\hline 28 & Bernardinho & 237 \\
\hline 29 & Padre Marcelo Rossi & 224 \\
\hline 30 & Zeca Baleiro & 220 \\
\hline 31 & Sílvio Santos & 219 \\
\hline
\end{tabular}

\begin{tabular}{|c|c|c|}
\hline Posição & Pessoa Famosa & $\begin{array}{c}\text { Valor } \\
\text { Absoluto }\end{array}$ \\
\hline 32 & Felipe Neto & 205 \\
\hline 33 & Pedro Bial & 203 \\
\hline 34 & Míriam Leitão & 195 \\
\hline 35 & Zeca Camargo & 182 \\
\hline 36 & Bóris Casoy & 181 \\
\hline 37 & Kaká & 176 \\
\hline 38 & Angélica & 170 \\
\hline 39 & Marco Luque & 166 \\
\hline 40 & Plínio & 157 \\
\hline 41 & Tony Ramos & 156 \\
\hline 42 & Xuxa & 150 \\
\hline 43 & Anderson Silva & 142 \\
\hline 43 & Glória Maria & 142 \\
\hline 45 & Silas Malafaia & 134 \\
\hline 46 & Pedro Andrade & 126 \\
\hline 47 & Sandy & 123 \\
\hline 48 & Cid Moreira & 112 \\
\hline 49 & Ronaldo (Fenômeno) & 100 \\
\hline 50 & Faustão & 92 \\
\hline 51 & Claudia Leite & 88 \\
\hline 51 & Romário & 88 \\
\hline 53 & João Dória & 87 \\
\hline 54 & Antônio Fagundes & 85 \\
\hline 55 & Marcos Palmeira & 75 \\
\hline 56 & Ronaldinho Gaúcho & 61 \\
\hline 57 & $\begin{array}{l}\text { Juninho Pernambu- } \\
\text { cano }\end{array}$ & 58 \\
\hline 57 & Sabrina Sato & 58 \\
\hline 59 & Elba Ramalho & 39 \\
\hline 60 & Thiago Neves & 34 \\
\hline 61 & Jorge e Mateus & 30 \\
\hline 62 & Francisco Silva & 11 \\
\hline
\end{tabular}

Fonte: Dados da pesquisa. 